\title{
Comparison of the effects of articaine, tetracaine, and lidocaine application on pain and hemorrhage during and after nasal pack removal
}

\author{
Vahit Mutlu* (1), Abdulkadir Kaya²
}

\begin{abstract}
SUMMARY
OBJECTIVE: We purposed to compare the effects of certain local anesthetic applications on pain and hemorrhage caused by nasal pack removal. METHODS: Design: Prospective, placebo-controlled study. Setting: Ataturk University Medical Faculty Hospital. This study was done in 90 patients who applied nasal packing after septoplasty. All patients were divided randomly into four groups. Each group was applied $2 \%$ lidocaine, $2 \%$ tetracaine, $4 \%$ articaine or $0.9 \%$ sodium chloride $(\mathrm{NaCl})$ into their Merocel packs 15 min before removing. Verbal analog scale (VAS) score was registered from all patients, and the amount of hemorrhage was noted during the removal of the nasal packs and then for $30 \mathrm{~min}$.

RESULTS: The study groups had significantly better pain scores than the control group during nasal pack removal and after 5 min $(p<0.001)$. The articaine and the lidocaine groups had also better pain scores than the control group at 15th min after the removal of the nasal packs $(p<0.05)$, but the tetracaine group had no better pain scores than the control group, which is statistically significant at $p>0.05$. Analysis of bleeding scores after the removal of packs showed that the articaine and the lidocaine groups had better bleeding scores than the control group ( $p<0.004$ and $p<0.033$, respectively).

CONCLUSION: Topical articaine application into nasal packs just before removing in the patients who underwent septoplasty can be safely used for less pain, less hemorrhage, and more patient tolerance.

KEYWORDS: Hemorrhage. Local anesthetic. Removal. Intranasal surgery. Pain.
\end{abstract}

\section{INTRODUCTION}

Septoplasty is one of the most commonly applied surgical procedures in the ear, nose, and throat clinics. Nasal packs are commonly used following septoplasty. This application prevents nasal bleeding and supports the septal mucoperichondrial flaps, thus preventing the risk of septal hematoma and intranasal adhesion in the postoperative period ${ }^{1}$. However, the removal of the nasal packs is a discomfort and painful procedure. The majority of patients who have undergone septoplasty express that the removal of the nasal pack was the most painful section of the septoplasty procedure ${ }^{2}$.
Different methods, such as the use of the packs with gel foam, blocking the sphenopalatine ganglion, and wetting the packs with local anesthetics before the removal of the nasal packs for the solution of this problem, have been reported in the literature ${ }^{3-5}$.

Lidocaine is an amide group local anesthetic and is effective in infiltration anesthesia and nerve block. It also penetrates into soft tissues rapidly. The commercial lidocaine form is $2 \%$ of lidocaine with adrenaline. The effect of this preparation is the medium duration and quick start. Its mean plasma half-life is $2 \mathrm{~h}^{6}$.

\footnotetext{
'Atatürk University Faculty of Medicine, Department of Otorhinolaryngology - Erzurum, Turkey.

${ }^{2}$ Adilcevaz Oncology Hospital, Department of Family Medicine - Bitlis, Turkey.

*Corresponding author: drvahit@gmail.com

Conflicts of interest: the authors declare there is no conflicts of interest. Funding: none.

Received on August 09, 2021. Accepted on September 07, 2021.
} 
Tetracaine is an ester group local anesthetic and is effective in spinal anesthesia and nerve block. In addition, it has good mucosal absorption. The effect of tetracaine is fast-acting, long term, having low risk of methemoglobinemia, and strong compared to other local anesthetics. The mean dose is $0.1-0.2 \mathrm{mg} /$ $\mathrm{kg}$, and the mean effect duration is $90-200 \mathrm{~min}^{7}$.

Articaine is both an amide group and an ester group local anesthetic due to its chemical structure. Articaine can easily cross the lipid-rich nerve membrane to access target receptors since it has greater lipid solubility compared to other amide group local anesthetics. It can be easily metabolized in the plasma and excreted from the primary kidney since it contains an ester group. It is effective in infiltration anesthesia, spinal anesthesia, and nerve block and penetrates into tissues, rapidly. Also, it does not negatively affect wound healing. Articaine is a local anesthetic, which has an intermediate potency, short-term effectiveness, and rapid onset of action. The onset of action is between 1 and $3 \mathrm{~min}$, and the average duration is $70 \mathrm{~min}^{8}$.

We aimed to investigate the effectiveness of these local anesthetics (i.e., lidocaine, tetracaine, and articaine) injected in nasal packs to reduce the pain, bleeding, and discomfort at the time of the removal of the packs and just after in patients who underwent a septoplasty. In this way, we purposed to correct the discomfort of patients and increase the tolerance of patients during the removal of the packs.

\section{METHODS}

This prospective, placebo-controlled study was performed at the Otorhinolaryngology Clinic of Ataturk University Medicine Faculty for 1 year. This study was approved by the Ethical Committee of the same faculty with approval number B.30.2.ATA.0.01.00/110, and informed consent was obtained from all patients.

This study included 90 patients aged $18-65$ years and applied nasal packing after septoplasty. The exclusion criteria included nasal polyposis, allergic rhinitis, chronic sinusitis, bleeding disorders, renal or hepatic disease, systemic infection, known allergy to the trial drugs, pregnancy, cardiac problems, and neurological or psychiatric disease.

Septoplasty operations were performed under general anesthesia by the same surgeon. Merocel intranasal packs were applied to both nasal cavities of all patients following septoplasty operation. Merocel nasal pack (Medtronic-Xomed, Jacksonville, FL, USA) is a hydroxylated polyvinyl acetate pack, which expands on contact with the fluid.

The patients were divided into four groups, and they were randomly included in the groups. Three of the four groups received one of the local anesthetics studied in our trial, and the control group received $0.9 \% \mathrm{NaCl}$. All packs were removed $48 \mathrm{~h}$ after the operation. The local anesthetic solutions and $\mathrm{NaCl}$ solution $(2.5 \mathrm{~mL}$ for each Merocel) were prepared by the clinic nurse. Both the patient and the surgeon were unaware of the used solution. Both the Merocel nasal packs of each patient were infiltrated with $2.5 \mathrm{~mL}$ either $2 \%$ lidocaine $+0.0012 \%$ adrenaline (Lidofast ${ }^{\circ}$, VEM, Turkey) or $2 \%$ tetracaine (Pantocaine) or $4 \%$ articaine $+0.0012 \%$ adrenaline (Ultracain ${ }^{\oplus}$, Sanofi, Turkey) or $0.9 \% \mathrm{NaCl}$ before the removal of the nasal packs. Nasal packs were removed $15 \mathrm{~min}$ after this application. Nasal pain and bleeding were evaluated during and after the removal of the nasal packs.

The patients were asked to mark the visual analog scale (VAS) at the 0-5-15-30th min after the removal of the nasal packs. The VAS values were evaluated using a ruler with a range of $0-10,0$ being no pain and 10 representing the worst pain imaginable. After the removal of the nasal packs, bleeding from both sides was recorded by the physician, who was blinded to the solution used, according to the following scale: $0=$ no bleeding, $1=$ mild bleeding just after the removal of the packs requiring no intervention, $2=$ moderate bleeding in the form of leakage for $0-5 \mathrm{~min}, 3=$ moderate bleeding in the form of leakage for $15 \mathrm{~min}$, and $4=$ significant bleeding requiring repacking or continuous bleeding for $30 \mathrm{~min}$. All outcomes were compared between the four groups, and the results were evaluated statistically.

Statistical analysis was performed using SPSS for Windows version 23.0 software program (IBM Corp., Armonk, NY, USA). The Student's $t$ test for continuous variables and the chi-square test for categorical variables were used, and a p value $<0.05$ was considered to be statistically significant.

Ethics Committee approval was obtained, and the written informed consent was obtained from all patients. This study was conducted adhering to the Declaration of Helsinki.

\section{RESULTS}

A total of 90 patients were enrolled for this study. All the patients completed the trial. The mean age of the patients was $33.05 \pm 11.10$ (range 18-65). The number of male patients was $63(70 \%)$ and female was $27(30 \%)$. The mean length of the patients was $172.03 \pm 7.5$ (range 154-192), and the average weight of the patients was $73.48 \pm 13.36$ (range 50-110).

Each of the study groups included 20 patients and the control group included 30 patients. The patients in the four groups were similar in terms of demographic parameters such as age, gender, race, geographical region, and culture.

Mean VAS values of the three study groups and the control group are provided in Table 1 and Figure 1. 
Table 1. Mean visual analog scores of groups according to time.

\begin{tabular}{|c|c|c|c|c|}
\hline & Groups & $\mathrm{n}$ & $\begin{array}{l}\text { Mean } \pm \text { standard } \\
\text { deviation }\end{array}$ & $p$ \\
\hline \multirow{4}{*}{$0 \mathrm{~min}$} & Control & 30 & $6.73 \pm 1.782$ & - \\
\hline & Lidocaine+A & 20 & $4.20 \pm 2.262$ & $<0.001$ \\
\hline & Tetracaine & 20 & $4.05 \pm 1.191$ & $<0.001$ \\
\hline & Articaine+A & 20 & $3.05 \pm 1.572$ & $<0.001$ \\
\hline \multirow{4}{*}{$5 \mathrm{~min}$} & Control & 30 & $3.77 \pm 1.870$ & - \\
\hline & Lidocaine+A & 20 & $0.90 \pm 1.294$ & $<0.001$ \\
\hline & Tetracaine & 20 & $0.30 \pm 0.979$ & $<0.001$ \\
\hline & Articaine+A & 20 & $0.00 \pm 0.000$ & $<0.001$ \\
\hline \multirow{4}{*}{$15 \min$} & Control & 30 & $0.43 \pm 0.817$ & - \\
\hline & Lidocaine+A & 20 & $0.00 \pm 0.000$ & 0.022 \\
\hline & Tetracaine & 20 & $0.10 \pm 0.447$ & 0.103 \\
\hline & Articaine+A & 20 & $0.00 \pm 0.000$ & 0.022 \\
\hline \multirow{4}{*}{$30 \mathrm{~min}$} & Control & 30 & $0.00 \pm 0.000$ & - \\
\hline & Lidocaine+A & 20 & $0.00 \pm 0.000$ & - \\
\hline & Tetracaine & 20 & $0.10 \pm 0.447$ & 0.224 \\
\hline & Articaine+A & 20 & $0.00 \pm 0.000$ & - \\
\hline
\end{tabular}

$+A$ : plus adrenaline. Statistically significant at $p<0.05$.

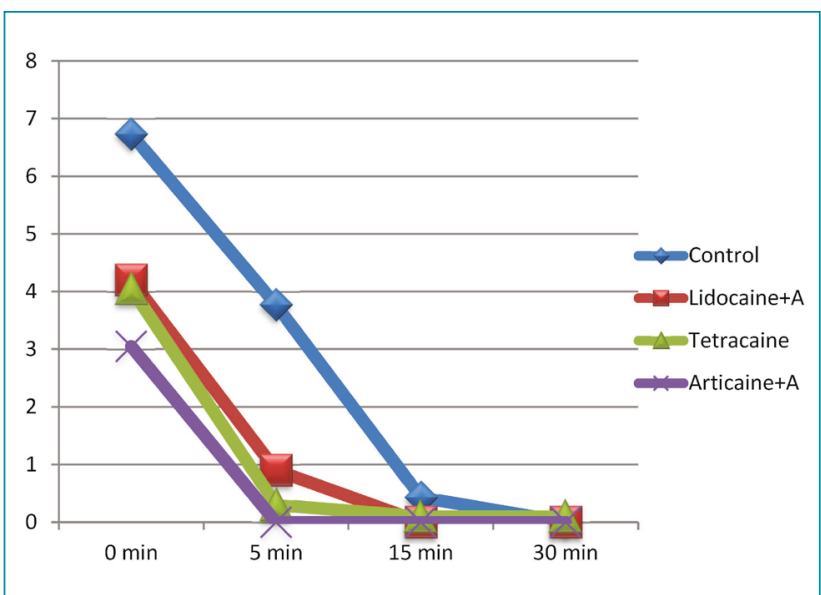

Figure 1. Mean visual analog scores of each group according to time points during and just after the removal of the nasal packs. The control group pain scores started from a high level, dropped rapidly in the first $15 \mathrm{~min}$, and then dropped slowly in the second $15 \mathrm{~min}$. Pain scores of lidocaine plus adrenaline group dropped rapidly in the first $5 \mathrm{~min}$, then descended slowly until 5th min, and then remained stable. Tetracaine group pain scores showed a rapidly dropping during the first $5 \mathrm{~min}$ and then slowly a drop. Articaine plus adrenaline pain scores decreased quickly in the first 5 min, after which they remained stable until the end of the observation period. +A: plus adrenaline.
All study groups had significantly better pain scores than the control group at 0 and 5 th $\min (\mathrm{p}<0.001)$. The lidocaine plus adrenaline and the articaine plus adrenaline groups had better pain scores than the control group at 15 th min after the removal of the nasal packs $(p=0.022)$. Although the tetracaine group had a better pain score than the control group, this result was not statistically significant $(\mathrm{p}=0.103)$. There was not a significant difference in terms of pain at 30th min. Almost all patients did not feel pain at 30th min. While the articaine plus adrenaline group had better pain scores than both study groups and the control group during $15 \mathrm{~min}$ after the removal of the packs, the lidocaine plus adrenaline group had the second best pain scores (Figure 1).

Mean hemorrhage values following the removal of the packs of three study groups and the control group are provided in Table 2 .

The articaine plus adrenaline group had a less bleeding rate compared to the both study groups and the control group $(\mathrm{p}=0.004)$. The lidocaine plus adrenaline group had the second less bleeding score $(\mathrm{p}=0.033)$. There was no statistically significant difference in terms of hemorrhage after the removal of the nasal packs between the tetracaine and the control groups ( $p>0.05$ ).

There were no side effects due to the use of medications in this study.

\section{DISCUSSION}

The most common problem after septoplasty is pain, and discomfort is seen during nasal packing and especially at the time of the removal of the packs and just after the procedure? In this study, we found that certain local anesthetics (i.e., lidocaine, tetracaine, and articaine), especially the articaine application to nasal packs, reduce the pain, bleeding, and discomfort formed during the removal of the packs of patients who underwent a septoplasty.

Table 2. Distribution of patients in the groups according to the Bleeding Scale.

\begin{tabular}{l|c|c|c|c|c|c|c}
\multirow{2}{*}{ Groups } & \multirow{5}{*}{$n$} & \multicolumn{5}{|c|}{$\begin{array}{c}\text { Distribution of } \\
\text { patients according } \\
\text { to Bleeding Scale }\end{array}$} & \multirow{2}{*}{$p$} \\
\cline { 3 - 7 } & & 0 & 1 & 2 & 3 & 4 & \\
\hline Control & 30 & 8 & 12 & 9 & 1 & 0 & - \\
\hline Lidocaine+A & 20 & 10 & 10 & 0 & 0 & 0 & 0.033 \\
\hline Tetracaine & 20 & 8 & 9 & 3 & 0 & 0 & 0.470 \\
\hline Articaine+A & 20 & 15 & 5 & 0 & 0 & 0 & 0.004 \\
\hline Total & 90 & 41 & 36 & 12 & 1 & 0 & \\
\hline
\end{tabular}

$+A$ : plus adrenaline. Statistically significant at $p<0.05$. 
Removal of the nasal packs is often the most uncomfortable and painful application of the septoplasty process for patients ${ }^{2}$. The cause of the pain may be due to the displacement of the blood clot and adherent tissues, following adherence of nasal tampons to the bleeding site and the mucosa in the nasal cavity ${ }^{10}$. Different applications have been described for reducing the effect of this discomfort and painful procedure. There are applications such as wrapping the packs with gel foam, blocking the sphenopalatine ganglion, use of preemptive analgesia, use of different packs, and wetting packs with topical local anesthetics in the literature ${ }^{3-5,11}$. There are also few studies reporting that nasal packing should not be used due to the discomfort that occurred while removing ${ }^{12}$.

The efficacy of some local anesthetics on pain and bleeding management during the removal of the packs has been reported before in the literature. In one study, the authors applied sphenopalatine ganglion block by using topical $1 \%$ lidocaine and found better analgesia versus the control group during the removal of the packs. However, this application required an invasive procedure ${ }^{4}$. Researchers have evaluated the efficacy of prilocaine and levobupivacaine on reducing pain and discomfort during the removal of nasal packs in a study. They included 72 patients who had undergone septoplasty or endoscopic sinus surgery in this trial. They found that the levobupivacaine or the prilocaine infiltration into the packs before the removal of the nasal packs can decrease discomfort and improve patient tolerability during the removal of the packs ${ }^{13}$. In another study, researchers have investigated the effect of local anesthetics, such as ropivacaine, lidocaine plus adrenaline, and bupivacaine, and found that bupivacaine provides better analgesia and does not cause increased bleeding during the removal of the packs ${ }^{6}$. In a study conducted using topical $2 \%$ lidocaine and $0.9 \%$ saline on the packs, the authors found no significant difference in terms of the pain scores between the groups ${ }^{14}$. In another study conducted to compare the effect of ropivacaine, bupivacaine, prilocaine, and lidocaine on reducing pain and hemorrhage during the removal of the nasal packs, the authors found that topical lidocaine application provides better pain and bleeding score compared to the other drugs ${ }^{2}$.

In this study, we investigated the effectiveness of the topical application of lidocaine plus adrenaline, tetracaine, and articaine plus adrenaline into nasal packs to reduce pain and bleeding during the removal of nasal packs. We found that the articaine had the best pain and bleeding scores, and the lidocaine had the second best pain and bleeding scores during the removal of the nasal packs.

The limitation of this study is a small sample size. Further studies with a large number of patient groups should be conducted.

\section{CONCLUSIONS}

In this study, local anesthetics, especially the articaine plus adrenaline topical applied into the packs before the removal of the nasal packs, provide better analgesia and less hemorrhage during the removal of the packs. In other words, topical articaine plus adrenaline application into nasal packs before removing in patients who underwent septoplasty can be safely used for less pain and bleeding and more patient tolerance during the removal of the packs.

\section{ETHICAL APPROVAL}

All procedures performed in studies involving human participants were in accordance with the Ethical Standards of the Institutional and/or National Research Committee (name the institution/ committee) and with the 1964 Helsinki Declaration and its later amendments or comparable ethical standards.

\section{INFORMED CONSENT}

Informed consent was obtained from all individual participants included in this study.

\section{AUTHORS' CONTRIBUTIONS}

VM: Conceptualization, Data curation, Formal analysis, Funding acquisition, Investigation, Methodology, Project administration, Resources, Software, Supervision, Validation, Visualization, Writing - original draft. AK: Conceptualization, Data curation, Formal analysis, Funding acquisition, Investigation, Methodology, Supervision, Writing - review \& editing.

\section{REFERENCES}

1. Ardehali MM, Bastaninejad S. Use of nasal packs and intranasal septal splints following septoplasty. Int J Oral Maxillofac Surg. 2009;38(10):1022-4. https://doi.org/10.1016/j.jjom.2009.05.012

2. Gencer ZK, Ozkiriş M, Gencer M, Saydam L. Comparison of ropivacaine, bupivacaine, prilocaine, and lidocaine in the management of pain and hemorrhage during nasal pack removal. Am J Rhinol Allergy. 2013;27(5):423-5. https://doi. org/10.2500/ajra.2013.27.3945

3. Apuhan T, Kocoglu H, Gulcu N. Comparison of lidocaine and levobupivacaine in transnasal fiberoptic laryngoscopy. Am J Rhinol Allergy. 2012;26(3):e104-6. https://doi.org/10.2500/ ajra.2012.26.3757 
4. Hwang JH, Liu CM, Liu TC, Hsu MC. Sphenopalatine ganglion block before removal of nasal packing. Laryngoscope. 2003;113(8):1423-4. https://doi.org/10.1097/00005537200308000-00030

5. Kuo MJ, Zeitoun H, Macnamara M, Wagstaff K, Carlin WV, Turner $\mathrm{N}$. The use of topical $5 \%$ lignocaine ointment for the relief of pain associated with post-operative nasal packing. Clin Otolaryngol Allied Sci. 1995;20(4):357-9. https://doi. org/10.1111/j.1365-2273.1995.tb00060.x

6. Karaman E, Gungor G, Alimoglu Y, Kilic E, Tarakci E, Bozkurt $P$, et al. The effect of lidocaine, bupivacaine and ropivacaine in nasal packs on pain and hemorrhage after septoplasty. Eur Arch Otorhinolaryngol. 2011;268(5):685-9. https://doi. org/10.1007/s00405-010-1432-7

7. Madineh H, Amani S, Kabiri M, Karimi B. Evaluation of the anesthetic effect of nasal mucosa with tetracaine $0.5 \%$ on hemodynamic changes and postoperative pain of septoplasty: a randomized controlled trial. J Adv Pharm Technol Res. 2017;8(4):116-9. https://doi.org/10.4103/japtr. JAPTR_8_17

8. Snoeck M. Articaine: a review of its use for local and regional anesthesia. Local Reg Anesth. 2012;5:23-33. https://doi. org/10.2147/LRA.S16682
9. Özkırış M, Kapusuz Z, Saydam L. Comparison of nasal packs with transseptal suturing after nasal septal surgery. Am J Otolaryngol. 2013;34(4):308-11. https://doi.org/10.1016/j. amjoto.2012.12.012

10. Chheda N, Katz AE, Gynizio L, Singer AJ. The pain of nasal tampon removal after nasal surgery: a randomized control trial. Otolaryngol Head Neck Surg. 2009;140(2):215-7. https:// doi.org/10.1016/j.otohns.2008.09.012

11. Hesham A, Ghali A. Rapid Rhino versus Merocel nasal packs in septal surgery. J Laryngol Otol. 2011;125(12):1244-6. https:// doi.org/10.1017/S0022215111002179

12. Orlandi RR, Lanza DC. Is nasal packing necessary following endoscopic sinus surgery? Laryngoscope. 2004;114(9):1541-4. https://doi.org/10.1097/00005537-200409000-00007

13. Apuhan T, Yildirim YS, Gulcu N, Koçoglu H, Karagöz Y. The effect of prilocaine or levobupivacaine infiltration on pain during nasal packing removal. Otolaryngol Head Neck Surg. 2011;145(3):41821. https://doi.org/10.1177/0194599811410660

14. Durvasula VSP, BrewIS C, Syeda F, Leong P. Lignocaine as a topical analgesia for post-operative nasal pack removal: a prospective, randomized, double-blind, controlled trial. J Laryngol Otol. 2005;119(5):348-51. https://doi. org/10.1258/0022215053945859 